DOI: https://doi.org/10.24867/05BE27Subotin

\title{
PREGLED SOFTVERSKIH ALATA ZA SIMULACIJU I ODABIR PARAMETARA TOPLOTNIH PUMPI
}

\section{OVERVIEW OF SOFTWARE TOOLS FOR SIMULATION AND SELECTION OF HEAT PUMP PARAMETERS}

\author{
Anja Subotin, Vladimir Katić, Fakultet tehničkih nauka, Novi Sad
}

\begin{abstract}
Elektrotehnika i računarstvo - Energetska elektronika i električne mašine
\end{abstract}

Kratak sadržaj - U ovom radu opisano je nekoliko odabranih softverskih alata za simulaciju $i$ odabir parametara toplotnih pumpi. Svaki od alata je ocenjen prema određenim kriterijumima, te je na kraju odabran softver koji je optimalan za simulaciju rada sistema. On je primenjen za simulaciju integracije toplotne pumpe $u$ sisteme za skladištenje tople $i$ hladne vode $i$ za simulaciju razlicitih kombinacija performansi toplotne pumpe vodavoda.

Ključne reči: Obnovljivi izvori energije, geotermalna energija, toplotne pumpe, softverski alati za simulaciju $i$ odabir parametara toplotnih pumpi.

\begin{abstract}
The paper describes several selected software tools for simulation and selection of heat pump parameteres. Each of the tools is evaluated according to certain criteria, and at the end, the optimal software is selected. It is used to simulate the integration of the heat pump into a hot and cold water storage systems and to simulate carious combinations of water-water heat pump performance.
\end{abstract}

Keywords: Renewable energy sources, geothermal energy, heat pump, software tools for simulation and selection of heat pump parameters.

\section{UVOD}

Poslednjih godina mnogo se govori o potrebi smanjenja potrošnje energije, odnosno povećanja energetske efikasnosti. Razlog tome je ubrzan rast tražnje vezan za globalni rast stanovništva i ubrzanu industrijalizaciju manje razvijenih zemalja, kao na primer Indije, Vijetnama, Nigerije, Angole i dr.

Rezerve fosilnih goriva su ograničene i troše se takvim tempom da se može očekivati njihovo iscrpljivanje već tokom ili najduže do kraja ovog veka. Istovremeno, njihovim korišćenjem se emituju razne čestice i gasovi staklene bašte, što ugrožava životnu sredinu i dovodi do pojave klimatskih promena. Iz tog razloga su u svetu pokrenut niz akcija za primenu tehnologija iskorišćavanja obnovljivih izvora energije, kao što su: energija biomase, solarna energija, energija vetra, vode i geotermalna energija.

\section{NAPOMENA:}

Ovaj rad proistekao je iz master rada čiji mentor je bio dr VladimirKatić, red.prof.
Jedan od načina za efikasnu upotrebu energije iz prirode, jeste primena geotermalne energije kroz tehnologiju toplotnih pumpi. Zahvaljujući najsavremenijim rešenjima, ovu energiju moguće je iskoristiti za pripremu vode ili vazduha za grejanje, a ujedno i za hlađenje. Efikasnost geotermalnog grejanja je znatno veća od standardnih oblika grejanja. Na primer, geotermalna energija je $48 \%$ efikasnija od kotlova na gas i više od $75 \%$ od peći na lož ulje. Njenim iskorišćavanjem ispušta se vrlo malo štetnih gasova $u$ atmosferu, pa je ovaj vid grejanja/hlađenja ekološki vrlo prihvatljiv [1].

Princip rada toplotnih pumpi predstavljen je na slici 1 . Putem izmenjivača toplote moguće je efikasno iskoristiti toplotnu energiju zemlje uz mali utrošak električne energije. Na taj način se može obezbediti oko $80 \%$ potreba objekta, dok se $20 \%$ mora utrošiti u vidu električne energije.

Pravilan odabir odgovarajućeg sistema i veličine toplotne pumpe veoma je važna faza u projektovanju ovih instalacija. On treba da ekonomično zagreva/hladi kuću tokom godine, ali $\mathrm{i}$ da se izbori sa najhladnijim i najtoplijim danima. Veća toplotna pumpa ima veće investicione troškove, ali i manje troškove rada, kao i obrnuto. Zato izbor veličine toplotne pumpe treba da da optimalni balans između investicionih i radnih troškova.

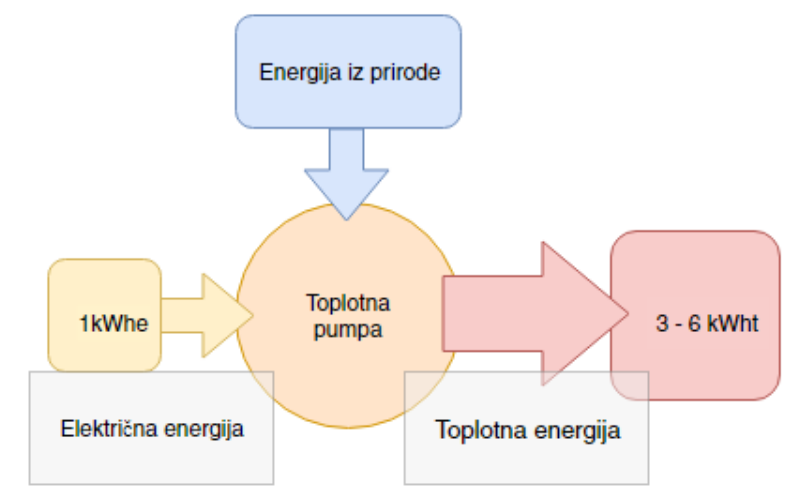

Slika 1. Princip rada toplotne pumpe.

Današnji softverski alati omogućavaju ovu optimizaciju i znatno olakšavaju i ubrzavaju proces odabira adekvatnog rešenja i projektovanje kompletnih sistema. Cilj ovog rada je da predstavi pregled svremenih softvera, koji su raspoloživi na tržištu. U obzir su uzeti sledeći softverski alati: GLD (Ground Loop Desing) softver, GeoT* SOL, Easy RSS, ETU softver, Solkane i TRNSYS. Takođe, cilj rada je i da preloži kriterijume za njihovo poređenje, te izvrši odabir najpovoljnijeg. 


\section{PREGLED SOFTVERSKIH ALATA}

U ovom poglavlju će biti ukratko predstavljene osnovne karakteristike pomenutih softverskih alata za proračun projektovanje sistema grejanja/hlađenja korišćenjem geotermalne energije na bazi tehnologije toplotnih pumpi.

\subsection{GLD (Ground Loop Design) softver}

Ground Loop Design (GLD) je vodeći softverski paket za projektovanje geotermalnih sistema toplotnih pumpi. Koristi se u više od 70 zemalja. Ovaj softver nudi set alata za brzo i automatsko dizajniranje cevnih sistema. Uključuje dva modula koji se odnose na dizajn cevovoda, a to su modul Piping Sistem Builder (PSB) i modul Computational Fluid Dinamics (CFD). Ova dva modula za projektovanje cevovoda bez problema se integrišu sa modulima dizajna izmenjivača toplote. Putem ove integracije, potrebno je samo nekoliko minuta da se dizajnira, optimizuje i odredi kompletan komercijalni cevovodni sistem [2].

Model toplotne pumpe koji se koristi u GLD programu reprodukuje kompletne operativne podatke bilo koje pojedinačne jedinice kada se isporučuje sa nekoliko reprezentativnih tačaka podataka izabranih iz celog interesnog područja. Podaci za svaku pumpu se mogu uneti u model i grupisati zajedno pod naslovom proizvođača i serije. Takođe, podaci se moraju uneti samo jednom, a zatim se mogu više puta koristiti za naredne sesije modelovanja. Mnoge popularne pumpe većih proizvođača su već uključene u program.

Neke od prednosti koje GLD softver pruža dizajnerima jesu: tačnost kalkulacije, pouzdan dizajn, lakoća korišćenja, brza iteracija i optimizacija, sveobuhvatna fleksibilnost i globalna podrška [2].

\subsection{GeoT* SOL softver}

GeoT* SOL je softver koji omogućava korisniku da bira između različitih izvora toplote i konfiguracija sistema. Ključna karakteristika je integracija solarnih termalnih sistema za toplu vodu za domaćinstvo ili grejanje prostora. Zahtevi, gubici i potrošnja se određuju kao rezultat dinamičke simulacije u minuti. Oni čine osnovu na kojoj se računaju potrošnja električne energije, godišnji koeficijent performansi i troškovi, uzimajući u obzir vanredne periode i tarife. Sa ovim parametrima GeoT* SOL softver procenjuje efikasnost sistema.

Uz pomoć ovog softvera, moguće je simulirati postojeće sisteme sa kotlom, gde je dodata toplotna pumpa. Nova postrojenja sa kotlom kao rezervom se uz pomoć GeoT* SOL softvera mogu prikazati i optimizovati. Način rada se može izabrati i parametrizovati za simulaciju iz velikog broja mogućih kombinacija monovalentnih, monoenergetskih i bivalentnih sistema sa paralelnim, delimično paralelnim ili alternativnim radom [3].

Sa GeoT * SOL softverom moguće je simulirati pet različitih tipova sistema toplotnih pumpi, od jednostavnih do vrlo složenih, svaki za konfiguraciju sa geotermalnim sondama za grejanje, vazduhom, geotermalnim kolektorima ili podzemnim vodama [3].

\subsection{Easy RSS softver}

Easy RSS je jedan od vodećih grupa u Velikoj Britaniji, koja nude softverska rešenja za obnovljive izvore energije. Ovaj softver za toplotne pumpe uključuje: dimenzionisanje toplotne pumpe, odabir pomoćnog ulaza, ishod sertifikata o usaglašenosti, proračun buke, dimenzionisanje uzemljenja, izračunavanje tekućih troškova, proračun kompenzacija za korišćenje sistema grejanja na bazi obnovljivih izvora u sklopu Renewable Heat Incentive (RHI) u Velikoj Britaniji [4].

Softver za toplotne pumpe nudi mogućnost korisniku da odredi veličine cevi na zemlji, proračuna buku i izračuna troškove. Pored područja za dizajniranje toplotnih pumpi, Easy RSS softver omogučava i proračun gubitaka toplote, emitera i kalkulaciju tople vode [4].

\subsection{ETU softver}

ETU Softver razvija, prodaje i podržava praktične softverske alate u oblasti inženjeringa, simulacije, verifikacije usklađenosti i finansijske opravdanosti usluga u sistemima obnovljivih izvora energije [5].

Svi ETU softverski proizvodi su napravljeni da budu: laki za upotrebu, pouzdani, pristupačni i ažurirani sa najnovijom tehnologijom.

ETU softverski proizvodi se mogu koristiti kao pojedinačna rešenja ili se mogu međusobno povezati: isti model zgrade može se koristiti za višestruke inženjerske/simulacione zadatke u celom procesu gradnje objekta, od običnih kalkulacija vrednosti do toplotne procene gubitaka ili hlađenja, dimenzionisanje HVAC opreme, projektovanje cevovodne mreže, hidrauličko balansiranje i dinamička simulacija izgradnje koja uključuje obnovljive izvore energije. ETU softverski alati se mogu koristiti za novogradnju i retro-fit objekte [5].

\subsection{Solkane softver}

Solkane je softverski paket za izračunavanje termofizičkih svojstava fluida razvijenih od strane nemačke kompanije Solkane, koja prodaje rashladna sredstva.Ovaj softverski paket uključuje i samostalnu aplikaciju za izvršavanje proračuna svojstava za različite rashladne fluide, kao i kompletne proračune ciklusa hlađenja sa kartama rashladnog sredstva, u kojima se mogu nacrtati ciklusi [6].

\subsection{TRNSYS softver}

Transient System Simulation Program (TRNSYS) je simulacioni program za energetske sisteme. TRNSYS je komercijalni softverski paket koji je razvijen na Univerzitetu Wisconsin. Jedna od prvobitnih primena je bila da se izvrši dinamička simulacija ponašanja solarnog sistema tople vode za tipičnu meteorološku godinu, kako bi se mogla utvrditi dugoročna ušteda takvog sistema [7]. Mnogi različiti energetski sistemi mogu se simulirati $u$ TRNSYS-u - sistemi za solarnu energiju, ventilacija i sistemi za grejanje vode u kućama i sistemi za kogeneraciju. Biblioteke komponenti sadrže komponente koje se koriste $\mathrm{u}$ različitim energetskim sistemima. Dodatne biblioteke komponenti mogu se kupiti zajedno sa TRNSYS-om. Najveća karakteristika ovog softvera su modularne analitičke metode [7].

\section{UPOREDNA ANALIZA SOFTVERA}

Softveri koji su navedeni u prethodnom poglavlju međusobno su analizirani i ocenjeni prema nekoliko, ovde postavljenih kriterijuma: 
1. funkcionalnost softvera,

2. korisnički intefejs,

3. baza podataka o vremenskim uslovima,

4. cena i dostupnost softvera.

Poređenje između softvera je urađeno kako bi se utvrdilo koji od ovih softvera je najbolji za simulaciju i odabir parametara toplotnih pumpi. Bitno je naglasiti da su u ovom radu korišćene probne verzije softvera. Takođe, ocenjivanje je izvršeno na bazi subjektivnog iskustva autora prilikom nabavke, instalacije, probnog rada $\mathrm{i}$ primene ovih sotvera.

Ukupna ocena svih softvera po navedenim kriterijumima je predstavljena na slici 2. Sa slike može se videti da je najbolje ocenjen softver TRNSYS, koji je ukupno dobio 16 od 20 mogućih poena.

U nastavku rada ovaj softver će biti iskorišćen za simulaciju integracije toplotne pumpe u sisteme $\mathrm{za}$ skladištenje tople i hladne vode i za simulaciju različitih kombinacija performansi toplotne pumpe voda-voda.

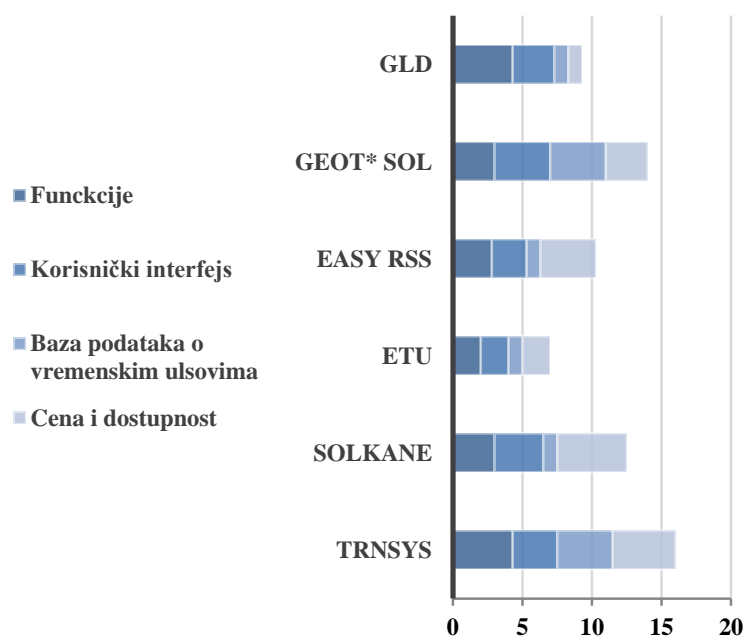

Slika 2. Uporedna analiza predstavljenih softverskih alata.

\section{PRIMERI PRIMENE ODABRANOG SOFTVERA}

Softver sa najboljim ocenama je TRNSYS softver. Uz pomoć ovog softvera određena je simulacija različitih kombinacija performansi toplotne pumpe tipa voda-voda za porodičnu kuću u Novom Kneževcu.

4.1. Simulacija različitih kombinacija performansi toplotne pumpe tipa voda-voda za kuću u Novom Kneževcu

Objekat se nalazi u Novom Kneževcu i predstavlja stambenu kuću na sprat od oko $120 \mathrm{~m}^{2}$. Kuća se greje na prirodni gas i prosečna mesečna potrošnja gasa za zimski period od 6 meseci je oko $350 \mathrm{~m}^{3}$. Grejanje u ovom prostoru vrši se preko radijatora.

Kada se posmatra na duži period, ovaj vid grejanja uopšte nije isplativ. Iz tog razloga je u ovom primeru primenjena simulacija različitih kombinacija performansi toplotne pumpe, čiji rezultat je sezonski grejni faktor (SPF) toplotne pumpe tipa voda-voda, ne bi li se smanjili troškovi grejanja.

$\mathrm{Na}$ sledećoj slici 3. prikazana je šema razvijenog modela u simulacijskom studiju u TRNSYS-u.

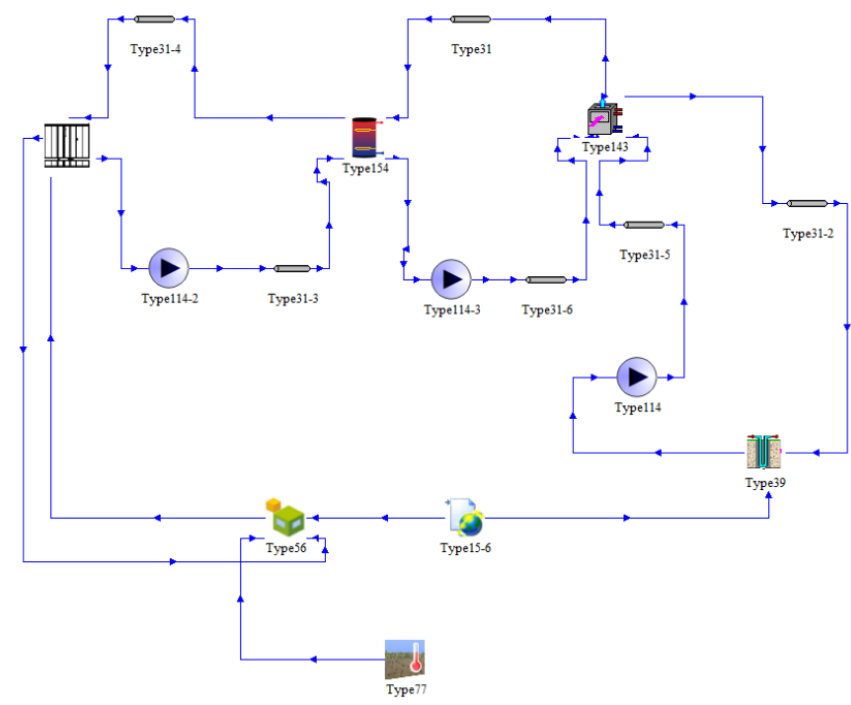

Slika 3. Šematski prikaz razvijenog modela u TRNSYS-u

Za modelovanje termalnog rezervoara, koji se smatra srcem razvijenog modela u TRNSYS-u, korišćen je vertikalni cilindrični termalni rezervoar. Definisana su dva priključka za povezivanje toplotne pumpe tipa vodavoda i sistem za distribuciju grejanja prostora (radijator) na termalni rezervoar. Čista voda se smatrala radnim fluidom.

Za modelovanje toplotne pumpe u TRNSYS-u, korišćena je jednofazna toplotna pumpa tipa voda-voda, koja je uzeta iz biblioteke (TYPE 668). Toplotna pumpa je modelovana tako da veličina odgovara nešto većoj od $70 \%$ maksimalne potrebe za grejanjem kuće. Stambeni objekat je građen 1991. godine, tako da je za specifično toplotno opterećenje uzeto $104 \mathrm{~W} / \mathrm{m}^{2}$. Iz sledećeg izraza (1) je dobijena ukupna potrebna energija za grejanje kuće.

$$
P_{e}=q * A
$$

Gde je q specifično toplotno opterećenje objekta, a A je ukupna neto površina stambenog objekta. Dobijeno je da je ukupna potrebna energija za grejanje ove kuće 12,48 $\mathrm{kW}$.

U sledećoj tabeli 1. prikazane su performanse toplotne pumpe tipa voda-voda.

Tabela 1. Performanse toplotne pumpe

\begin{tabular}{|c|c|c|c|}
\hline $\begin{array}{c}\text { Temperatura } \\
\text { ulaznog } \\
\text { izvora }\left[{ }^{\circ} \mathrm{C}\right]\end{array}$ & $\begin{array}{c}\text { Temperatura } \\
\text { ulaznog } \\
\text { opterećenja } \\
{\left[{ }^{\circ} \mathrm{C}\right]}\end{array}$ & $\begin{array}{c}\text { Kapacitet } \\
\text { grejanja } \\
\text { toplotne } \\
\text { pumpe } \\
{[\mathrm{kW}]}\end{array}$ & $\begin{array}{c}\text { Ulazna } \\
\text { snaga } \\
\text { toplotne } \\
\text { pumpe } \\
{[\mathrm{kW}]}\end{array}$ \\
\hline-10 & 25 & 8,195 & 2,036 \\
\hline-10 & 35 & 8,173 & 2,58 \\
\hline-10 & 45 & 8,228 & 3,266 \\
\hline-10 & 55 & 8,359 & 4,12 \\
\hline-5 & 25 & 9,4 & 2,085 \\
\hline-5 & 35 & 9,279 & 2,608 \\
\hline-5 & 45 & 9,203 & 3,257 \\
\hline
\end{tabular}




\begin{tabular}{|c|c|c|c|}
\hline-5 & 55 & 9,166 & 4,07 \\
\hline 0 & 25 & 10,757 & 2,147 \\
\hline 0 & 35 & 10,538 & 2,665 \\
\hline 0 & 45 & 10,335 & 3,291 \\
\hline 0 & 55 & 10,124 & 4,064 \\
\hline 5 & 25 & 12,265 & 2,216 \\
\hline 5 & 35 & 11,946 & 2,739 \\
\hline 5 & 45 & 11,618 & 3,353 \\
\hline 5 & 55 & 11,229 & 4,096 \\
\hline 10 & 25 & 13,921 & 2,284 \\
\hline 10 & 35 & 13,501 & 2,823 \\
\hline 10 & 45 & 13,044 & 3,436 \\
\hline 10 & 55 & 12,479 & 4,16 \\
\hline 15 & 25 & 15,714 & 2,344 \\
\hline 15 & 35 & 15,195 & 2,913 \\
\hline 15 & 45 & 14,602 & 3,534 \\
\hline 15 & 55 & 13,858 & 4,249 \\
\hline
\end{tabular}

\section{ZAKLJUČAK}

Primena obnovljivih izvora energije i njihovo eksploatisanje je od velike važnosti i predstavlja bitan segment energetsko-ekološke strategije razvijenih zemalja. Najefikasnija primena geotermalnih toplotnih pumpi je za zagrevanje i hlađenje. Ovakav vid korišćenja njenih potencijala može se primeniti kako za grejanje tako i hlađenje stambenih, industrijskih i drugih tipova objekata. Ono što je najbitnije kod ovakvih sistema jeste njegova energetska efikasnost koja može iznositi i 70\% u odnosu na druge sisteme grejanja. Ako se uzme u obzir da se ovom investicijom rešava grejanje $\mathrm{i}$ da postoji mogućnost hlađenja prostora onda je ušteda pri radu toplotne pumpe znatno veća.

\section{LITERATURA}

[1] Dragana Gašić, „Analiza primjene toplotne pumpe za grijanje i klimatizaciju poslovnog prostora", Diplomski rad, Fakultet tehničkih nauka, Novi Sad, 2018.

[2] www.groundloopdesign.com/ (pristupeljeno u junu 2019.)

$\mathrm{Za}$ modelovanje izvora toplote (voda) u TRNSYS-u, korišćen je vertikalni izmenjivač toplote U-tipa. Radni fluid dobija toplotu iz dubine zemlje u U-tipu izmenjivača toplote i pumpa se u isparivač toplotne pumpe gde se vrši izmena toplote između radnog fluida $\mathrm{i}$ rashladnog sredstva toplotne pumpe.

\subsection{Rezultati simulacije}

Kao rezultat ove simulacije dobijena prosečna vrednost koeficijenta efikasnosti (COP), oko 5,4. U tabeli 2. prikazani su ostali rezultati simulacije.

Tabela 2. Rezultati simulacije

\begin{tabular}{|l|c|}
\hline Veličina toplotne pumpe [kW] & 11,62 \\
\hline $\begin{array}{l}\text { Godišnja energija dobijena toplotnom } \\
\text { pumpom [kWh/god] }\end{array}$ & 27250 \\
\hline SPF [kWh/god] & 2,7 \\
\hline
\end{tabular}

Ukupna potrebna električna energija za rad toplotne pumpe tokom cele godine je dobijena iz sledećeg izraza (2):

$$
P_{\text {god el.en. }}=\frac{P_{\text {god }}}{C O P}=\frac{27250}{5,4}=5046,3 \mathrm{Kwh}
$$

$\mathrm{Na}$ osnovu dobijenih rezultata iz simulacije može se zaključiti da je ulaganje u toplotnu pumpu isplativo na dugoročni period. Ako se uzme u obzir da je cena prirodnog gasa veoma visoka, toplotne pumpe tipa vodavoda predstavljaju najekonomičniji vid grejanja, iako su početna ulaganja dosta veća.

Ekonomičnost toplotnih pumpi ogleda se se, pre svega, u što većem koeficijentu grejanja koji predstavlja odnos količine toplotne energije, koju isporučuje toplotna pumpa i količine električne energije potrebne za rad toplotne pumpe. Od svih alternativnih grejanja najveću perspektivu imaju toplotne pumpe (tipa voda - voda), jer su se pokazale kao ekonomični sistemi za grejanje u dobro izolovanim kućama.

[3] www.valentin-softwar.com/ (pristupeljeno u junu 2019.)

[4] www.easy-rss.co.uk (pristupeljeno u junu 2019.)

[5] www.etu-software.com (pristupeljeno u junu 2019.)

[6] M. Sikora, "Parameters selection of a heat pump using the Solkane software", Koszalin University of Technology (KTU), Poljska, 2017

[7] www.trnsys.com/demo/ (pristupeljeno u junu 2019.)

[8] S.M. Al Zahrani, F.L Tan, F.H. Choo, "A TRNSYS Simulation Case Study on Utilization of Heat Pump For both Heating and Coolin", Nanyang Technological University, 2012

[9] H.K. Bakhtiari, "Developing a dynamic model of ground-source heat pump system to evaluate different components size", Department of Energy Technology, SE-100 44, Stokhlom, Švedska

\section{Kratka biografija:}

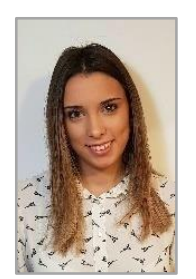

Anja Subotin je rođena u Novom Kneževcu 1993. god. Diplomirala je na Fakultetu tehničkih nauka 2016. god. sa temom "Idejno rešenje napajanja kuće u Novom Kneževcu iz obnovljivih izvora energije". Iste godine upisuje Master akademske studijena Fakultetu tehničkih nauka iz oblasti Elektrotehnike i računarstva-Elektroenergetski sistemi. Master rad je odbranila 2019.god.

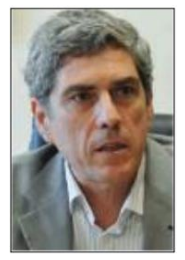

Vladimir Katić je rođen 1954. god. u Novom Sadu. Doktorirao je na Univerzitetu u Beogradu 1991. god. Od 2002. god. je redovni profesor Univerziteta u Novom Sadu. Trenutno je i prodekan Fakulteta tehničkih nauka i šef katedre za energetsku elektroniku i pretvarače. Oblasti interesovanja su energetska elektronika, obnovljivi izvori energije, električna vozila i kvalitet električne energije. 